\title{
Five-Factor Model personality profiles of drug users
} Antonio Terracciano*1, Corinna E Löckenhoff ${ }^{1}$, Rosa M Crum² ${ }^{2} \mathrm{O}$ Joseph Bienvenu ${ }^{2}$ and Paul T Costa Jr ${ }^{1,2}$

Address: ${ }^{1}$ National Institute on Aging, NIH, DHHS, Baltimore, USA and ${ }^{2}$ Johns Hopkins Bloomberg School of Public Health, Baltimore, USA

Email: Antonio Terracciano* - TerraccianoA@grc.nia.nih.gov; Corinna E Löckenhoff - loeckenhoffc@grc.nia.nih.gov; Rosa M Crum - rcrum@jhsph.edu; O Joseph Bienvenu - jbienven@mail.jhmi.edu; Paul T Costa - costap@grc.nia.nih.gov

* Corresponding author

Published: II April 2008

BMC Psychiatry 2008, 8:22 doi:10.1/86/147|-244X-8-22
Received: 9 November 2007

Accepted: II April 2008

This article is available from: http://www.biomedcentral.com/I47I-244X/8/22

(C) 2008 Terracciano et al; licensee BioMed Central Ltd.

This is an Open Access article distributed under the terms of the Creative Commons Attribution License (http://creativecommons.org/licenses/by/2.0), which permits unrestricted use, distribution, and reproduction in any medium, provided the original work is properly cited.

\begin{abstract}
Background: Personality traits are considered risk factors for drug use, and, in turn, the psychoactive substances impact individuals' traits. Furthermore, there is increasing interest in developing treatment approaches that match an individual's personality profile. To advance our knowledge of the role of individual differences in drug use, the present study compares the personality profile of tobacco, marijuana, cocaine, and heroin users and non-users using the wide spectrum Five-Factor Model (FFM) of personality in a diverse community sample.
\end{abstract}

Method: Participants $(N=1,102$; mean age $=57)$ were part of the Epidemiologic Catchment Area (ECA) program in Baltimore, MD, USA. The sample was drawn from a community with a wide range of socio-economic conditions. Personality traits were assessed with the Revised NEO Personality Inventory (NEO-PI-R), and psychoactive substance use was assessed with systematic interview.

Results: Compared to never smokers, current cigarette smokers score lower on Conscientiousness and higher on Neuroticism. Similar, but more extreme, is the profile of cocaine/ heroin users, which score very high on Neuroticism, especially Vulnerability, and very low on Conscientiousness, particularly Competence, Achievement-Striving, and Deliberation. By contrast, marijuana users score high on Openness to Experience, average on Neuroticism, but low on Agreeableness and Conscientiousness.

Conclusion: In addition to confirming high levels of negative affect and impulsive traits, this study highlights the links between drug use and low Conscientiousness. These links provide insight into the etiology of drug use and have implications for public health interventions.

\section{Background}

Drug use is related to adverse health and social outcomes [1]. Cigarette smoking is a leading cause of preventable disability and death in the U.S. and around the world [2], increasing the risk of cancer, cardiovascular disease, respiratory and other health problems $[3,4]$. The use of other psychoactive substances, most of them illicit drugs, is also associated with massive social cost beyond the damage to the individual users, affecting health care, law enforcement, and legal systems $[1,5]$. 
The high individual and social costs of drug use highlight the need to study factors related to such behaviors. Even if personality differences between drug users and non-users are generally small, these effects can have important clinical implications due to the large number of people involved. Research on the correlates of drug addiction provides insights for understanding etiology and inform prevention policies and cessation programs. For example, from a psychiatric perspective, a number of studies have documented the high comorbidity of drug use with other mental disorders [6-10], which indicate that mood, anxiety, and personality disorders need to be considered by drug treatment specialists to achieve successful intervention. The present study contributes to this line of research by examining the personality traits associated with current and lifetime drug use in an economically-diverse community sample. Specifically, we attempt to replicate previously reported associations among personality traits and smoking status and extend the analyses to users of marijuana, heroin, and cocaine. Comparing personality profiles, we examine similarities and differences in traits associated with a variety of drugs used. Although the high rate of multiple drug use complicates comparisons across substances, results may point to specific traits that underlie the use of a specific drug as well as common factors across different types of drug use.

The present study adopts the well-validated Five-Factor Model of personality [11] which comprehensively covers the five major traits that define human personality across cultures $[12,13]$ : Neuroticism $(\mathrm{N})$, the tendency to experience negative emotions such as anxiety and depression; Extraversion (E), the tendency to be sociable, warm, active, assertive, cheerful, and in search of stimulation; Openness to Experience $(\mathrm{O})$, the tendency to be imaginative, creative, unconventional, emotionally and artistically sensitive; Agreeableness (A), the dimension of interpersonal relations, characterized by altruism, trust, modesty, and cooperativeness; and Conscientiousness (C), a tendency to be organized, strong-willed, persistent, reliable, and a follower of rules and ethical principles. Each of these factors is hierarchically defined by specific facets, which can provide a more in-depth description of drug users' personalities.

In previous studies, cigarette smokers were found to score high on facets related to impulsivity and Neuroticism, and low on Agreeableness and Conscientiousness [14-16]. However, in European and Asian studies and some older US studies, smokers were also found to score high on Extraversion [16-18]. Compared to cigarette smoking, there are fewer studies on the personality correlates of illegal drug use, and these are based on smaller sample sizes and a variety of personality measures. A meta-analysis [19] examined personality correlates of marijuana use cat- egorizing traits into "negative affect" (e.g., depression, anxiety), "emotionality" (e.g., extraversion, social disinhibition), and "unconventionality" (e.g., tolerance of deviance, non-religiosity). These measures map loosely onto Neuroticism, Extraversion, and Openness, respectively. Results suggested that marijuana use was related to high levels of unconventionality, and only weakly to emotionality and negative affect. Another meta-analysis [20] examined the role of a wide range of Conscientiousnessrelated measures on health risk behaviors. Across studies, a consistent association was found between marijuana use (as well as other drug use) and low scores on Conscientiousness-related traits. Cocaine users are characterized by high scores on Neuroticism-related traits $[21,22]$, such as depression and impulsivity $[23,24]$, as well as Psychoticism $[21,22]$, a trait related to low Agreeableness and low Conscientiousness. Finally, studies of heroin users consistently depict them as high on Neuroticism [25-28]. Many studies show an association of heroin use with high Extraversion and high Psychoticism, but this association appears to be less robust [26-28]. Inconsistencies in the association of personality and drug use are due to several factors, such as differences in the personality measures used, inadequate sample sizes, and socio-cultural differences. Most studies use measures that capture only a subset of relevant personality traits, and rarely assess all five major factors and their facets. Studies are also hampered by reliance on small convenience samples. This is particularly true for studies on the use of illegal drugs. Further, with few exceptions, studies have focused on a single substance at a time, making it difficult to detect common patterns across a range of different drugs. This study extends previous research by examining multiple types of drug use in a large population-based sample while utilizing a wellvalidated and comprehensive measure of personality that captures both global factors and specific facets of personality.

\section{Method \\ Participants}

Participants were drawn from the East Baltimore Epidemiologic Catchment Area Study (Baltimore ECA) [29], a multidisciplinary study which is based on a probability sample of 3,481 East Baltimore residents who were initially interviewed in 1981 and followed up in 1992-98 and in 2004-05. Personality traits were assessed at the two most recent waves. To maximize the sample size, cross-sectional analyses were conducted on the last valid personality assessments $(N=1,102), 80 \%$ of which were obtained in 2004-05. At the time of the personality assessments, age ranged from 30 to 94 years $(M=56.6 ; S D$ $=12.4$ ), and participants had an average of 12.5 years of education $(S D=2.6)$. About $62 \%$ of the sample was female; $63 \%$ were White/Non-Hispanic, 34\% were Black/ Non-Hispanic, and 3\% other or unknown ethnic group. 
To screen out cognitively impaired individuals, participants with Mini Mental State Scores [30] below the cut-off value of 23 were excluded.

As could be expected, participants who completed the personality measure at follow-up were those who in 1981 were younger ( 35 vs. 54 years old; $p<.01$ ) and more educated ( 12.5 vs. 9.7 years of education; $p<.01$ ), as compared to those who did not complete the personality assessment (because of mortality, sample loss, or subject refusal). There were no significant differences in the proportion of males and females or ethnic groups (Fisher's exact test: $p>.05)$.

\section{Drug use assessment and prevalence}

Trained interviewers asked questions about substance use after participants signed the informed consent approved by the ethics committee. The form assured the confidentiality of the answers, and that those were used for research purposes only. Participation was voluntary, and subjects could withdraw at any time. Subjects received $\$ 20$ after the interview.

Cigarette smoking status was determined by responses to interview questions, asking participants whether they had ever smoked tobacco cigarettes and when they smoked their last cigarette. Of the 1,088 participants without missing data, we classified "never smokers" as those who never smoked $(n=341)$, "former smokers" as those who smoked but not in the last seven days $(n=429)$, and current smokers as those who smoked in the last seven days $(n=318)$. Use ranged from fewer than 10 cigarettes $(40 \%)$ to over 20 cigarettes a day (16\%), with a majority smoking between 11 and 20 cigarettes a day (44\%).

Marijuana use was determined by responses to questions on whether participants had ever used either marijuana or hashish, even once, and when they last used marijuana or hashish. Of the 1044 individuals without missing data, about $55 \%$ of the sample responded that they never tried marijuana or hashish $(n=576), 36 \%$ used it but not in the past-year $(n=380)$, and $8 \%$ did use it in the last-year $(n=$ 88 ). Among the past-year current users, about $20 \%$ used marijuana daily or almost daily, about $45 \%$ used it from once or twice a week to once or twice a month, and about $35 \%$ used it between once and eleven times a year.

Cocaine use was determined by responses to questions on whether participants had ever used cocaine (including all forms of cocaine, such as powder, "crack," freebase, and coca paste) even once, and when they last used any form of cocaine. Of the 1094 individuals without missing data, about $82 \%$ had never tried cocaine $(n=896)$, about $16 \%$ used it but not in the past-year $(n=170)$, and about $3 \%$ did use it in the last-year $(n=28)$. Among the past-year current users, about $14 \%$ used cocaine daily or almost daily, about $43 \%$ used it from once or twice a week to once or twice a month, and about $43 \%$ used it between once and eleven times a year.

Heroin use was determined by responses to questions on whether participants had ever used heroin, even once, and when they last used it. Of the 1094 individuals without missing data, about $93 \%$ had never tried heroin $(n=$ $1023)$, about $6 \%$ used it but not in the past-year $(n=62)$, and about $1 \%$ used it in the last-year $(n=9)$. Of the nine past-year current users, three individuals used heroin daily or almost daily, two used it from once or twice a week to once or twice a month, and four used it between once and eleven times a year. Given the small number of current heroin users, and given that eight out of nine current heroin users were also current cocaine users, and $87 \%$ of the former heroin users were also former or current cocaine users, we examined the association of personality traits with cocaine or heroin use. As expected in a populationbased sample, we also found substantial overlap among the other drugs used. Of the former and current smokers, $52 \%$ had also used marijuana, $21 \%$ cocaine, and $8 \%$ heroin. About $78 \%$ of current and former marijuana users had also smoked cigarettes, $40 \%$ had used cocaine, and $15 \%$ heroin. About $82 \%$ of current and former heroin/ cocaine users had also smoked cigarettes and 98\% had used marijuana. Demographic information by drug type is given in Table 1: Across substances, current users were younger; males were more likely to use marijuana and cocaine/heroin, but there were no sex differences in cigarette smoking; African-Americans were more likely to use substances; and low education was associated with higher use of substances, with the exception of marijuana.

\section{Personality assessment}

Participants completed the self-report questionnaire at home or at a participating institution. The Revised NEO Personality Inventory [NEO-PI-R, [31]] consists of 240 items answered on a five-point Likert format ranging from strongly disagree to strongly agree. The NEO-PI-R assesses 30 facets, six for each dimension of the FFM (see Table 2 for a listing of the 30 facet scales). Raw scores were standardized as $T$-scores $(M=50, S D=10)$ using combined-sex adult norms reported in the Manual [31]. The NEO-PI-R has been translated into several languages and used in more than 50 cultures [12]. Evidence of convergent and discriminant validity is presented in the Manual [31], and a large literature demonstrates cross-observer agreement and prediction of external criteria such as psychological well-being, health risk behaviors, educational and occupational achievements, coping mechanisms, and longevity [31,32]. In a previous study [33] we tested the validity of personality assessment in the ECA sample and found 
Table I: Demographic statistics by drug type.

\begin{tabular}{|c|c|c|c|c|c|}
\hline Group & $\mathrm{N}$ & Age & Female & African-American & Education \\
\hline Never smoker & 341 & 58 & $64 \%$ & $30 \%$ & 12.9 \\
\hline Former smoker & 429 & 59 & $60 \%$ & $30 \%$ & 12.6 \\
\hline Current smoker & 318 & 52 & $62 \%$ & $45 \%$ & 11.9 \\
\hline Marijuana: never-user & 576 & 62 & $69 \%$ & $30 \%$ & 12.1 \\
\hline Marijuana: former-user & 380 & 50 & $53 \%$ & $37 \%$ & 13.0 \\
\hline Marijuana: current-user & 88 & 48 & $44 \%$ & $47 \%$ & 12.4 \\
\hline Cocaine/heroin: never-user & 887 & 59 & $65 \%$ & $32 \%$ & 12.4 \\
\hline Cocaine/heroin: former-user & 178 & 48 & $46 \%$ & $39 \%$ & 12.9 \\
\hline Cocaine/heroin: current-user & 29 & 46 & $48 \%$ & $59 \%$ & 11.9 \\
\hline Total & 1102 & 57 & $62 \%$ & $34 \%$ & 12.5 \\
\hline
\end{tabular}

Note. Mean age and education expressed in years. For age, ethnicity, and education there were significant differences between never, former, and current users of cigarettes, marijuana, and cocaine/heroin. Sex differences were seen for marijuana and cocaine/heroin users, but not for cigarette smoking.

adequate alpha reliabilities, retest-stability, and factor structure of the NEO-PI-R scales.

\section{Statistical analyses}

All analyses were performed using SPSS 13.0 [34]. For each drug, we performed a MANCOVA with user status as the independent variable, personality factors and facets as the dependent variables, and age, sex, education, and ethnicity as covariates. Post-hoc comparisons among never, former, and current users groups were based on LSD estimates. The assumption of homogeneity of variance was tested using the Levene statistic, and no large violations were found. Effect sizes were estimated using partial $\eta^{2}$. According to Cohen [35], $\eta^{2}$ values of $0.0099,0.0588$ and 0.1379 correspond to small, medium and large effect sizes, respectively.

\section{Results}

\section{Personality traits and smoking status}

Multivariate analyses of covariance controlling for demographic variables indicated significant personality differences among smoking status groups (see Table 2). Compared to never smokers, current smokers scored higher on Neuroticism and lower on Conscientiousness. Current smokers scored lower on Agreeableness, but this difference was not significant after controlling for demographic variables. Former smokers scored intermediate on Neuroticism and Conscientiousness. At the facet level, current smokers were characterized by traits related to the construct of impulsivity, (i.e., N5:Impulsiveness, E5:Excitement-Seeking, C5:Self-Discipline, and C6:Deliberation) [36]. Smokers as a group were also high on N3:Depression, N6:Vulnerability, and low in A4:Compliance, C1:Competence, and C3:Dutifulness. Although the magnitude of the effects is small, the differences among groups are consistent with the findings from previous studies [14]. Figure 1 plots the full profile of current smokers against current users of marijuana and cocaine/ heroin, as well as never user of these substances. The Figure presents estimated marginal means after partialling out the demographic covariates. Former users are excluded.

\section{Personality traits and marijuana use}

Compared to never users, current marijuana users scored higher on Openness and lower on Agreeableness and Conscientiousness (see Table 3). Former users scored intermediate on these three factors. On the facet level, current marijuana users scored higher on four facets of Openness, particularly Openness to O6:Values and O5:Ideas, and lower on five facets of Conscientiousness, particularly C3:Dutifulness and C6:Deliberation. Other interesting effects for current marijuana users were the high scores on N2:Angry Hostility, N6:Vulnerability, E4:Activity, and E5:Excitement Seeking, and the low scores on A4:Compliance, as compared to never users. As depicted in Figure 1, the profile of current marijuana users is similar to the pattern found among current smokers, especially for the facets of Conscientiousness.

\section{Personality traits and cocaine/heroin use}

Compared to never users, current cocaine/heroin users scored higher on Neuroticism and lower on Conscientiousness (see Table 4). Former cocaine/heroin users scored lower on Conscientiousness, but did not differ from never-users on Neuroticism. On the facet level, current users scored high on all facets of Neuroticism, with large effect sizes (difference larger than one $S D$ ) on N6:Vulnerability, high on E5:Excitement Seeking, low on A1:Trust, A2:Straightforwardness, and A4:Compliance, 

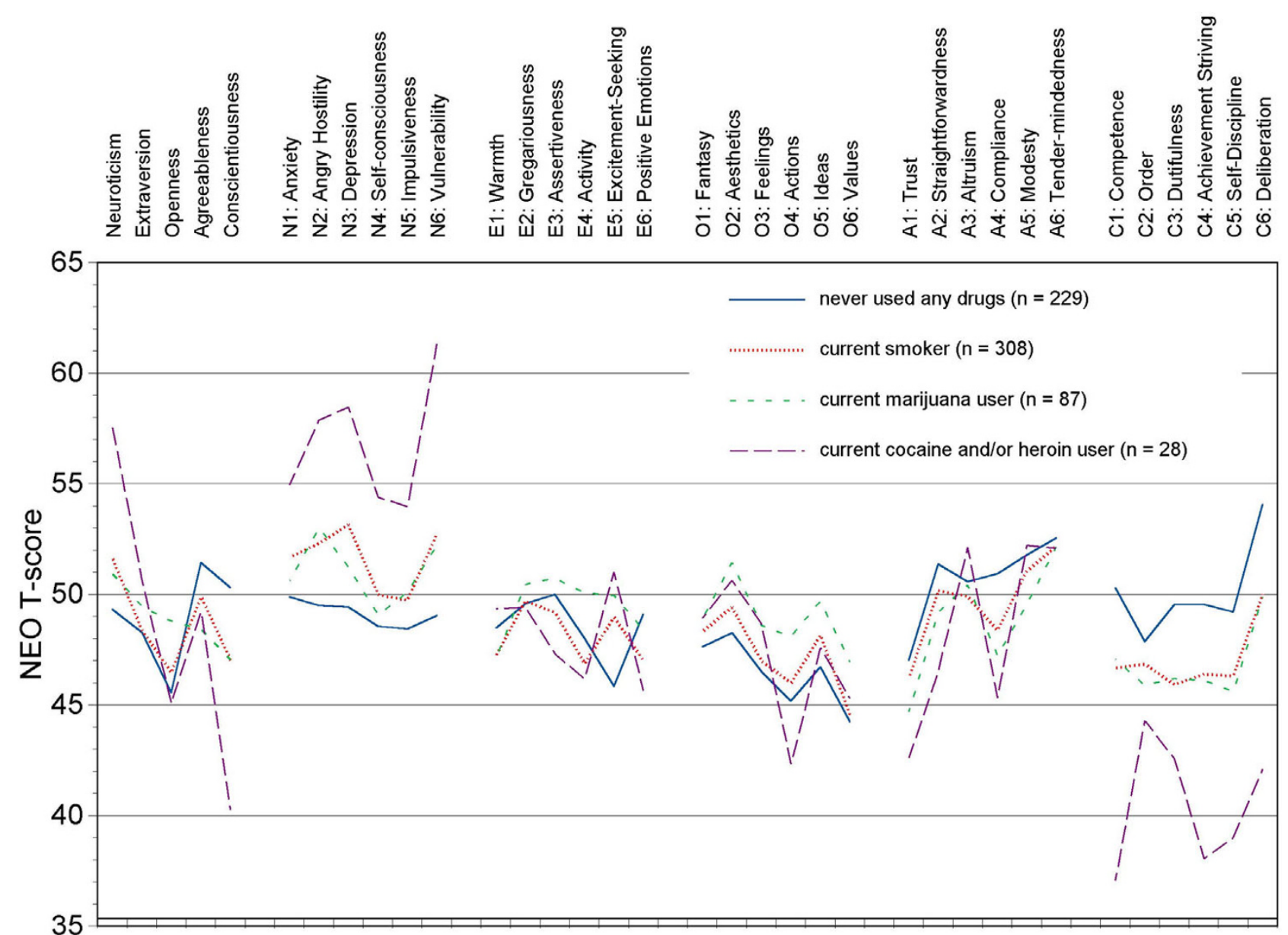

Figure I

NEO-PI-R profile of current users of tobacco, marijuana, and cocaine/heroin and never users of those substances. Plots show estimated marginal means after controlling for age, sex, ethnicity, and education.

and very low on all facets of Conscientiousness, with differences larger than one $S D$ on C1:Competence, C4:Achievement Striving, and C6:Deliberation. The profile of cocaine/heroin current users is illustrated in Figure 1 , which resembles the pattern seen for current smokers, but the profile of cocaine/heroin users is more extreme. Additional analyses indicated that although the few individuals $(n=9)$ who used both cocaine and heroin had the most extreme profile, the individuals who were current users of cocaine but not heroin also scored significantly higher on Neuroticism and lower on Conscientiousness than never users.

\section{Discussion}

The associations observed in the Baltimore ECA sample are consistent with the existing literature, which finds drug users generally high on measures of negative emotionality or psychopathology and low on Conscientious- ness $[8,9,20,37]$. Most previous studies have analyzed a limited number of traits (often omitting the crucial Conscientiousness factor) or focused on a single substance, making it difficult to integrate the body of evidence across traits or substances. Using a more integrative approach, this study indicates that low Conscientiousness and high Neuroticism are consistently associated with tobacco smoking, heroin, and cocaine use. Low Conscientiousness is also characteristic of marijuana users, who are average on Neuroticism and high on Openness, a trait that distinguishes marijuana users from other drug users. The present study extends the previous literature by assessing higher-level personality factors as well as lower-level facets. The association among Neuroticism and tobacco/heroin/cocaine use was found for all six facets of Neuroticism, indicating that multiple aspects of negative emotionality and psychopathology are involved in this effect. With the exception of C2:Order, low scores on all 
Table 2: Mean personality traits for never, former, and current cigarette smokers.

\begin{tabular}{|c|c|c|c|c|c|}
\hline NEO-PI-R scales & Never-smokers $(n=34 I)$ & Former-smokers $(n=429)$ & Current-smokers $(n=3 \mid 8)$ & $F$ & Partial $\eta^{2}$ \\
\hline Neuroticism & $48.9(.51)^{\mathrm{a}}$ & $50.7(.46)^{b}$ & $51.6(.55)^{\mathrm{b}}$ & $6.9 * *$ & .013 \\
\hline Extraversion & $48.8(.44)$ & $49.3(.40)$ & $48.4(.48)$ & 1.0 & .002 \\
\hline Openness & $45.6(.44)$ & $46.4(.39)$ & $46.5(.47)$ & 1.2 & .002 \\
\hline Agreeableness & $50.9(.49)$ & $50.9(.44)$ & $49.9(.52)$ & 1.3 & .002 \\
\hline Conscientiousness & $49.4(.52)^{\mathrm{a}}$ & $49.0(.46)^{a}$ & $47.0(.55)^{\mathrm{b}}$ & $5.5^{* *}$ & .010 \\
\hline NI: Anxiety & $49.7(.46)^{\mathrm{a}}$ & $5 \mathrm{I} .0(.4 \mathrm{I})^{\mathrm{b}}$ & $51.7(.50)^{\mathrm{b}}$ & $4.7^{* *}$ & .009 \\
\hline N2: Angry Hostility & $49.5(.50)^{\mathrm{a}}$ & $50.7(.45)^{\mathrm{a}}$ & $52.3(.54)^{\mathrm{b}}$ & $6.9 * *$ & .013 \\
\hline N3: Depression & $49.3(.57)^{\mathrm{a}}$ & $50.8(.5 \mathrm{I})^{\mathrm{a}}$ & $53.1(.61)^{b}$ & $10.0 * *$ & .019 \\
\hline N4: Self-consciousness & $48.4(.52)^{\mathrm{a}}$ & $50.1(.46)^{b}$ & $50.0(.56)^{\mathrm{b}}$ & $3.6^{*}$ & .007 \\
\hline N5: Impulsiveness & $48.3(.48)^{\mathrm{a}}$ & $49.8(.43)^{b}$ & $49.7(.52)^{b}$ & $3.4^{*}$ & .007 \\
\hline N6: Vulnerability & $49.3(.58)^{\mathrm{a}}$ & $50.4(.52)^{\mathrm{a}}$ & $52.7(.63)^{b}$ & $7.9 * *$ & .015 \\
\hline EI: Warmth & $48.9(.52)$ & $48.4(.46)$ & $47.2(.56)$ & 2.4 & .005 \\
\hline E2: Gregariousness & $50.5(.50)$ & $51.0(.45)$ & $49.7(.54)$ & 1.7 & .003 \\
\hline E3: Assertiveness & $50.1(.51)$ & $49.6(.46)$ & $49.2(.55)$ & 0.7 & .001 \\
\hline E4: Activity & $48.1(.49)$ & $47.3(.43)$ & $46.9(.52)$ & 1.5 & .003 \\
\hline E5: Excitement-Seeking & $46.9(.47)^{\mathrm{a}}$ & $47.7(.42)^{\mathrm{a}}$ & $49.0(.50)^{b}$ & $4.4^{*}$ & .008 \\
\hline E6: Positive Emotions & $48.9(.5 \mathrm{I})^{\mathrm{a}}$ & $48.9(.46)^{\mathrm{a}}$ & $47.0(.55)^{b}$ & $3.9 *$ & .007 \\
\hline OI: Fantasy & $47.8(.44)$ & $48.5(.39)$ & $48.3(.47)$ & 0.7 & .001 \\
\hline O2: Aesthetics & $48.3(.48)$ & $49.4(.43)$ & $49.4(.52)$ & 1.7 & .003 \\
\hline O3: Feelings & $46.7(.46)$ & $47.6(.4 I)$ & $47.0(.50)$ & 1.2 & .002 \\
\hline O4: Actions & $45.2(.50)$ & $46.1(.45)$ & $46.0(.54)$ & 1.0 & .002 \\
\hline O5: Ideas & $46.5(.48)$ & $46.9(.43)$ & $48.1(.52)$ & 2.7 & .005 \\
\hline O6: Values & $45.0(.45)$ & $45.6(.40)$ & $44.6(.48)$ & 1.4 & .003 \\
\hline AI: Trust & $47.2(.53)$ & $46.6(.47)$ & $46.2(.57)$ & 0.9 & .002 \\
\hline A2: Straightforwardness & $50.7(.50)$ & $51.0(.44)$ & $50.2(.53)$ & 0.7 & .001 \\
\hline A3: Altruism & $50.2(.52)^{\mathrm{a}}$ & $51.6(.46)^{b}$ & $49.9(.55)^{\mathrm{a}}$ & $3.5^{*}$ & .007 \\
\hline A4: Compliance & $50.5(.55)^{\mathrm{a}}$ & $48.8(.49)^{\mathrm{b}}$ & $48.4(.59)^{\mathrm{b}}$ & $3.8^{*}$ & .007 \\
\hline A5: Modesty & $50.9(.50)$ & $51.5(.45)$ & $51.1(.54)$ & 0.3 & .001 \\
\hline A6: Tender-mindedness & $52.0(.50)$ & $52.4(.44)$ & $52.2(.53)$ & 0.2 & .000 \\
\hline $\mathrm{Cl}$ : Competence & $50.0(.56)^{\mathrm{a}}$ & $49.9(.50)^{\mathrm{a}}$ & $46.7(.60)^{b}$ & $10.2 * *$ & .019 \\
\hline C2: Order & $47.5(.47)$ & $47.0(.42)$ & $46.8(.5 \mathrm{I})$ & 0.5 & .001 \\
\hline C3: Dutifulness & $49.0(.51)^{\mathrm{a}}$ & $48.5(.45)^{\mathrm{a}}$ & $45.9(.55)^{\mathrm{b}}$ & $9.0 * *$ & .017 \\
\hline C4: Achievement Striving & $49.0(.55)^{\mathrm{a}}$ & $48.4(.49)^{a}$ & $46.4(.58)^{b}$ & $5.4 * *$ & .010 \\
\hline C5: Self-Discipline & $48.6(.55)^{\mathrm{a}}$ & $47.7(.49)^{\mathrm{a}}$ & $46.3(.59)^{\mathrm{b}}$ & $3.8^{*}$ & .007 \\
\hline C6: Deliberation & $53.5(.53)^{\mathrm{a}}$ & $52.6(.48)^{a}$ & $50.0(.57)^{\mathrm{b}}$ & $10.1 * *$ & .019 \\
\hline
\end{tabular}

Note. Estimated marginal means (Standard Errors), statistical tests, and effect sizes computed after controlling for age, sex, ethnicity (black, white), and education $(n=1058)$.

Means with different superscripts differ significantly at $p<.05$.

$* p<.05 ; * * p<.01$

facets of Conscientiousness were associated with drug use. Although Extraversion showed no association with drug use on the factor level, facet-level analyses revealed a consistent association between high scores on E5:ExcitementSeeking and all types of drug use. This finding is not surprising given that, together with N5:Impulsiveness (inability to resist cravings), C5:Self-Discipline (limited ability to stay on task), and C6:Deliberation (lack of careful consideration of the consequences of one's actions), the E5:Excitement-Seeking facet is an aspect of impulsivity [36]. The selective association between drug use and this specific Extraversion facet also suggests that inconsistent findings for Extraversion may be due to Extraversion measures that differ in their relative emphasis on the excitement-seeking component.
Cross-sectional association analyses provide limited input on the cause and effect relation between personality traits and drug use. Although individual differences in personality traits are particularly stable in adulthood [38-40], some evidence suggests that substance use influences personality-related variables [41]. Cigarette smoking contributes to stress, negative affect states, and the onset of clinical correlates of Neuroticism, such as anxiety and depressive disorders [42-44]. Piedmont [45] reported substantial declines in Neuroticism and increases in Agreeableness and Conscientiousness in a group of polysubstance abusers following a rehabilitation program [26] (but see [28]). Consistently, smoking cessation is associated with lower Neuroticism scores, a lower level of stress, and lower risk of anxiety disorders $[42,44]$. Another 
Table 3: Mean personality traits for never, non-current, and current marijuana users.

\begin{tabular}{|c|c|c|c|c|c|}
\hline NEO-PI-R scales & Never-user $(n=576)$ & Former user $(n=380)$ & Current user $(n=88)$ & $F$ & Partial $\eta^{2}$ \\
\hline Neuroticism & $50.0(.42)$ & $50.4(.50)$ & $50.9(1.01)$ & 0.4 & .001 \\
\hline Extraversion & $49.0(.37)$ & $48.5(.44)$ & $49.4(.88)$ & 0.7 & .001 \\
\hline Openness & $45.5(.37)^{\mathrm{a}}$ & $46.1(.44)^{\mathrm{a}}$ & $48.8(.88)^{b}$ & $5.5^{* *}$ & .011 \\
\hline Agreeableness & $51.6(.40)^{\mathrm{a}}$ & $49.6(.49)^{b}$ & $48.4(.98)^{b}$ & $6.3 * *$ & .012 \\
\hline Conscientiousness & $49.7(.43)^{\mathrm{a}}$ & $47.0(.5 \mathrm{I})^{\mathrm{b}}$ & $47.0(1.03)^{b}$ & $8.0^{* *}$ & .016 \\
\hline NI: Anxiety & $50.5(.38)$ & $50.8(.46)$ & $50.6(.92)$ & 0.1 & .000 \\
\hline N2: Angry Hostility & $50.0(.41)^{\mathrm{a}}$ & $51.2(.50)^{\mathrm{ab}}$ & $53.0(1.00)^{b}$ & $3.9 *$ & .008 \\
\hline N3: Depression & $50.4(.47)$ & $5 \mathrm{I} .4(.57)$ & $51.2(1.14)$ & 0.7 & .001 \\
\hline N4: Self-consciousness & $49.2(.43)$ & $50.0(.5 I)$ & $49.1(1.03)$ & 0.7 & .001 \\
\hline N5: Impulsiveness & $48.7(.40)$ & $49.7(.48)$ & $50.1(.96)$ & 1.4 & .003 \\
\hline N6: Vulnerability & $49.6(.47)^{\mathrm{a}}$ & $51.5(.57)^{b}$ & $52.2(1.15)^{b}$ & $3.7^{*}$ & .007 \\
\hline EI: Warmth & $49.1(.43)^{\mathrm{a}}$ & $47.1(.52)^{\mathrm{b}}$ & $47.1(1.03)^{\mathrm{ab}}$ & $4.2^{*}$ & .008 \\
\hline E2: Gregariousness & $50.8(.4 I)$ & $50.1(.50)$ & $50.4(1.00)$ & 0.5 & .001 \\
\hline E3: Assertiveness & $49.7(.42)$ & $49.4(.5 \mathrm{I})$ & $50.7(1.03)$ & 0.7 & .001 \\
\hline E4: Activity & $47.4(.40)^{\mathrm{a}}$ & $46.9(.48)^{\mathrm{a}}$ & $50.1(.97)^{b}$ & $4.6^{*}$ & .009 \\
\hline E5: Excitement-Seeking & $47.1(.39)^{a}$ & $48.5(.47)^{b}$ & $49.9(.94)^{b}$ & $4.3^{*}$ & .009 \\
\hline E6: Positive Emotions & $49.0(.42)$ & $47.4(.5 \mathrm{I})$ & $48.4(1.02)$ & 2.3 & .005 \\
\hline Ol: Fantasy & $47.9(.36)$ & $48.5(.44)$ & $48.9(.87)$ & 0.8 & .001 \\
\hline O2: Aesthetics & $48.5(.40)^{\mathrm{a}}$ & $49.0(.48)^{\mathrm{a}}$ & $51.4(.96)^{b}$ & $3.9^{*}$ & .008 \\
\hline O3: Feelings & $46.6(.38)$ & $47.3(.46)$ & $48.6(.92)$ & 1.9 & .004 \\
\hline O4: Actions & $45.2(.42)^{\mathrm{a}}$ & $45.9(.50)^{\mathrm{a}}$ & $48.1(1.01)^{b}$ & $3.2^{*}$ & .006 \\
\hline O5: Ideas & $47.2(.40)^{\mathrm{a}}$ & $46.2(.49)^{\mathrm{a}}$ & $49.7(.97)^{b}$ & $5.7^{* *}$ & .011 \\
\hline O6: Values & $44.0(.37)^{\mathrm{a}}$ & $46.1(.44)^{\mathrm{b}}$ & $46.9(.89)^{b}$ & $7.9 * *$ & .015 \\
\hline Al: Trust & $47.3(.43)$ & $46.5(.52)$ & $44.7(1.04)$ & 2.7 & .005 \\
\hline A2: Straightforwardness & $51.4(.4 I)$ & $50.0(.49)$ & $49.2(.99)$ & 2.9 & .006 \\
\hline A3: Altruism & $5 \mathrm{I} .4(.42)^{\mathrm{a}}$ & $49.4(.5 \mathrm{I})^{\mathrm{b}}$ & $50.4(1.03)^{\mathrm{ab}}$ & $3.8^{*}$ & .008 \\
\hline A4: Compliance & $50.4(.45)^{\mathrm{a}}$ & $48.2(.55)^{b}$ & $47.2(1.10)^{b}$ & $5.4^{* *}$ & .011 \\
\hline A5: Modesty & $51.9(.42)$ & $50.7(.50)$ & $49.5(1.01)$ & 2.8 & .006 \\
\hline A6: Tender-mindedness & $52.5(.4 I)$ & $51.6(.50)$ & $52.2(.99)$ & 1.0 & .002 \\
\hline $\mathrm{Cl}$ : Competence & $50.0(.47)^{\mathrm{a}}$ & $47.7(.56)^{b}$ & $47.1(1.13)^{b}$ & $5.0 * *$ & .010 \\
\hline C2: Order & $47.6(.39)$ & $46.5(.48)$ & $45.9(.95)$ & 2.1 & .004 \\
\hline C3: Dutifulness & $49.2(.42)^{\mathrm{a}}$ & $46.2(.5 \mathrm{I})^{\mathrm{b}}$ & $46.2(1.01)^{b}$ & $9.8^{* *}$ & .019 \\
\hline C4: Achievement Striving & $49.0(.45)^{\mathrm{a}}$ & $46.6(.55)^{b}$ & $46.1(1.09)^{b}$ & 6.0 ** & .012 \\
\hline C5: Self-Discipline & $48.7(.46)^{\mathrm{a}}$ & $46.5(.55)^{b}$ & $45.6(1.10)^{b}$ & $5.3^{* *}$ & .010 \\
\hline C6: Deliberation & $53.2(.44)^{\mathrm{a}}$ & $50.9(.54)^{\mathrm{b}}$ & $49.9(1.07)^{b}$ & $6.6 * *$ & .013 \\
\hline
\end{tabular}

Note. Estimated marginal means (Standard Errors), statistical tests, and effect sizes computed after controlling for age, sex, ethnicity (black, white), and education $(n=1013)$.

Means with different superscripts differ significantly at $p<.05$.

$* p<.05 ; * * p<.01$

set of evidence suggests that personality traits are risk factors for psychoactive substance use, along with social environment and life experiences [46,47]. For example, in long term longitudinal studies, low Conscientiousness in childhood predicts cigarette smoking in adulthood $[48,49]$. Longitudinal studies in Europe also suggest that high scores on Neuroticism and Extraversion during adolescence increase the likelihood of being a smoker later in life $[18,50]$. A common hypothesis is that individuals with high Neuroticism use drugs to self-medicate [51,52]. Finally, third variables might be responsible for the association of personality and addictive behaviors. For example, personality traits and cigarette smoking are both highly heritable $[53,54]$, and could be influenced by common genetic factors [37].

\section{Limitations}

There are several limitations to consider when interpreting the results. This sample is not representative of the entire US population, but it was drawn from a probability sample that included a wide range of socio-economic conditions. There may be some misclassification with the categories of never, former, and current-users. For example, some individuals might be reluctant to disclose their illicit drug use. Some might not recall use in the distant past. Categorizing current users based on self-reported behavior during the past year might be too broad. There are marked differences in the frequency and quantity of drug use, but the relatively small number of users in the present sample does not allow finer distinctions or the use of stricter criteria of addiction. However, preliminary analy- 
Table 4: Mean personality traits for never, non-current, and current cocaine/heroin users.

\begin{tabular}{|c|c|c|c|c|c|}
\hline NEO-PI-R scales & Never-user $(n=887)$ & Former user $(n=178)$ & Current user $(n=29)$ & $F$ & Partial $\eta^{2}$ \\
\hline Neuroticism & $50.3(.32)^{\mathrm{a}}$ & $49.7(.73)^{\mathrm{a}}$ & $57.6(1.77)^{\mathrm{b}}$ & $8.8^{* *}$ & .016 \\
\hline Extraversion & $48.5(.28)$ & $50.0(.63)$ & $50.7(1.54)$ & 2.7 & .005 \\
\hline Openness & $46.1(.28)$ & $46.7(.63)$ & $45.1(1.54)$ & 0.7 & .001 \\
\hline Agreeableness & $50.8(.31)$ & $49.9(.69)$ & $49.2(1.69)$ & 1.1 & .002 \\
\hline Conscientiousness & $49.2(.32)^{\mathrm{a}}$ & $46.8(.73)^{b}$ & $40.3(1.77)^{c}$ & $14.7^{* *}$ & .027 \\
\hline NI: Anxiety & $51.0(.29)^{\mathrm{a}}$ & $49.5(.66)^{b}$ & $54.9(1.62)^{c}$ & $5.6 * *$ & .010 \\
\hline N2: Angry Hostility & $50.4(.31)^{\mathrm{a}}$ & $5 \mathrm{I} .4(.7 \mathrm{I})^{\mathrm{a}}$ & $57.9(1.73)^{\mathrm{b}}$ & $9.1 * *$ & .017 \\
\hline N3: Depression & $50.8(.36)^{\mathrm{a}}$ & $51.0(.82)^{\mathrm{a}}$ & $58.5(1.99)^{b}$ & $7.2^{* *}$ & .013 \\
\hline N4: Self-consciousness & $49.6(.32)^{\mathrm{a}}$ & $48.5(.74)^{\mathrm{a}}$ & $54.4(1.80)^{\mathrm{b}}$ & $4.9 * *$ & .009 \\
\hline N5: Impulsiveness & $49.0(.30)^{\mathrm{a}}$ & $50.0(.69)^{\mathrm{a}}$ & $54.0(1.68)^{\mathrm{b}}$ & $4.7^{* *}$ & .009 \\
\hline N6: Vulnerability & $50.5(.36)^{\mathrm{a}}$ & $50.2(.82)^{a}$ & $61.3(2.01)^{b}$ & $14.4^{* *}$ & .027 \\
\hline El: Warmth & $48.1(.32)$ & $48.7(.74)$ & $49.3(1.80)$ & 0.4 & .001 \\
\hline E2: Gregariousness & $50.3(.31)$ & $51.2(.7 I)$ & $49.4(1.74)$ & 0.9 & .002 \\
\hline E3: Assertiveness & $49.6(.32)$ & $50.0(.73)$ & $47.3(1.78)$ & 1.0 & .002 \\
\hline E4: Activity & $47.3(.30)$ & $48.5(.69)$ & $46.2(1.69)$ & 1.7 & .003 \\
\hline E5: Excitement-Seeking & $47.2(.29)^{\mathrm{a}}$ & $50.0(.66)^{b}$ & $51.0(1.62)^{b}$ & $8.7^{* *}$ & .016 \\
\hline E6: Positive Emotions & $48.4(.32)$ & $48.0(.73)$ & 45.7 (1.79) & 1.2 & .002 \\
\hline OI: Fantasy & $48.1(.28)$ & $48.7(.63)$ & $48.9(1.53)$ & 0.5 & .001 \\
\hline O2: Aesthetics & $48.9(.30)$ & $49.6(.69)$ & $50.6(1.68)$ & 0.8 & .002 \\
\hline O3: Feelings & $47.0(.29)$ & $47.3(.66)$ & $48.7(1.61)$ & 0.5 & .001 \\
\hline O4: Actions & $45.5(.31)^{\mathrm{a}}$ & $47.5(.7 I)^{b}$ & $42.3(1.74)^{\mathrm{a}}$ & $5.4^{* *}$ & .010 \\
\hline O5: Ideas & $47.2(.31)$ & $46.8(.69)$ & $47.6(1.69)$ & 0.2 & .000 \\
\hline O6: Values & $44.7(.28)^{\mathrm{a}}$ & $46.9(.64)^{b}$ & $45.3(1.55)^{\mathrm{ab}}$ & $4.8^{* *}$ & .009 \\
\hline Al: Trust & $47.1(.33)^{\mathrm{a}}$ & $45.4(.74)^{b}$ & $42.6(1.82)^{b}$ & $4.5^{*}$ & .008 \\
\hline A2: Straightforwardness & $50.9(.31)^{\mathrm{a}}$ & $50.2(.70)^{\mathrm{a}}$ & $46.5(1.72)^{\mathrm{b}}$ & $3.3^{*}$ & .006 \\
\hline A3: Altruism & $50.6(.32)$ & $50.7(.73)$ & $52.1(1.79)$ & 0.4 & .001 \\
\hline A4: Compliance & $49.4(.34)^{\mathrm{a}}$ & $49.0(.78)$ & $45.3(1.91)$ & 2.3 & .004 \\
\hline A5: Modesty & $51.2(.32)$ & $51.2(.72)$ & $52.2(1.75)$ & 0.2 & .000 \\
\hline A6: Tender-mindedness & $52.2(.31)$ & $52.5(.71)$ & $52.1(1.72)$ & 0.1 & .000 \\
\hline $\mathrm{Cl}$ : Competence & $49.7(.35)^{\mathrm{a}}$ & $47.4(.79)^{b}$ & $37.0(1.92)^{c}$ & $22.3^{* *}$ & .041 \\
\hline C2: Order & $47.2(.29)$ & $47.1(.67)$ & $44.3(1.63)$ & 1.5 & .003 \\
\hline C3: Dutifulness & $48.3(.32)^{\mathrm{a}}$ & $46.4(.73)^{\mathrm{b}}$ & $42.5(1.77)^{c}$ & $7.2^{* *}$ & .014 \\
\hline C4: Achievement Striving & $48.5(.34)^{\mathrm{a}}$ & $46.7(.77)^{b}$ & $38.1(1.87)^{c}$ & $15.9^{* *}$ & .029 \\
\hline C5: Self-Discipline & $48.1(.34)^{\mathrm{a}}$ & $46.1(.78)^{b}$ & $39.0(1.91)^{c}$ & $12.6 * *$ & .023 \\
\hline C6: Deliberation & $52.7(.33)^{\mathrm{a}}$ & $51.0(.75)^{\mathrm{a}}$ & $42.1(1.84)^{b}$ & $16.6^{* *}$ & .031 \\
\hline
\end{tabular}

Note. Estimated marginal means (Standard Errors), statistical tests, and effect sizes computed after controlling for age, sex, ethnicity (black, white), and education $(n=1062)$.

Means with different superscripts differ significantly at $p<.05$.

$* p<.05 ; * * p<.01$

ses using different classification criteria produced similar results, and the main findings are mostly consistent with the literature. In addition to self-report ratings, future studies should use multiple methods for assessing drug use and personality traits.

Most studies on drug use are conducted in adolescents and young adults, who are at life stages associated with the greater use of drugs. We presented data from an older cohort, which has presumably passed the experimentation age. While this contributes to the scarce literature on drug use in later parts of the lifespan, the advantages of a lifespan perspective come at the cost of having fewer current users in this older cohort. In addition, older cohorts only include the survivors among those who started drug use early in life, which may introduce attrition and other biases. A review of the literature [20] suggested that studies that involve older populations (over the age of 30 years) report weaker association of Conscientiousnessrelated traits and drug use.

Finally, some of the findings may be culture-bound [55]. For example, the results for smoking closely replicate the findings we previously reported from another US cohort of similar age but different socio-economic status. However, studies conducted in Europe [50] and Japan [17] have found Extraversion associated with cigarette smoking [16]. Such differences might reflect the different social acceptance of smoking across countries. 


\section{Conclusions: Clinical and social policy implications}

Personality traits are associated with the outcome of therapeutic interventions. For example, several studies found Neuroticism, anxiety, and depressive disorders related to poor treatment outcome for nicotine dependence [56]. Although we found systematic differences between the personality profiles of substance users and non-users, there is substantial variability in both groups (e.g., not all smokers score high on Neuroticism or low on Conscientiousness). Individual differences among substance abusers can play an important role in the choice of treatment options [57]. Recently, more attention has been focused on personality trait effects on the efficacy of different treatment plans [58] to tailor therapeutic interventions to individual needs $[59,60]$. More research is needed to fully evaluate how personality assessment can be useful in the choice of treatment plans.

Although individual treatments might reduce the rate of drug abuse, public policy is an important tool for cigarette smoking and other drug abuse prevention and cessation. Because of the low conscientiousness, high impulsivity, and high emotional vulnerability of most drug users, relying on an individual's resources, without therapeutic intervention, may produce limited results. Evidencebased interventions such as safer injecting environments are an important adjunct which can reduce drug-related harm [61]. In the case of cigarette smoking, societal pressure in the form of high taxation, restriction in advertising, and interdiction of smoking in public places are costeffective programs that are reducing the prevalence of smoking [62].

\section{Competing interests}

Paul T. Costa, Jr. receives royalties from the Revised NEO Personality Inventory. The authors declare that they have no other competing interests.

\section{Authors' contributions}

The ECA is an ongoing longitudinal study in which PTC, $\mathrm{OJB}$, and RMC are active research members that participate in its conception, design, and coordination. AT conceived the current manuscript, performed the statistical analysis, and drafted the manuscript. CEL, PTC, RMC, and OJB contributed to the conception and draft of the manuscript. PTC coordinated the work for the manuscript. All authors read and approved the final manuscript.

\section{Acknowledgements}

This research was supported in part by the Intramural Research Program of the NIH, National Institute on Aging, and by NIH grants MH47447, $\mathrm{MH} 50616$, and K23-MH64543.

\section{References}

I. Nutt D, King LA, Saulsbury W, Blakemore C: Development of a rational scale to assess the harm of drugs of potential misuse. Lancet 2007, 369(9566): 1047-1053.

2. World Health Organization: The World Health Report 2002 -Reducing risks, promoting healthy life. Geneva, World Health Organization; 2002.

3. World Health Organization: The facts about smoking and health. [http://www.wpro.who.int/media centre/fact sheets/ fs 20020528.htm].

4. U.S. Department of Health and Human Services: The health consequences of smoking: A report of the Surgeon General. Washington, U.S. Department of Health and Human Services, Centers for Disease Control and Prevention, National Center for Chronic Disease Prevention and Health Promotion, Office on Smoking and Health; 2004.

5. Reuter P: What drug policies cost: estimating government drug policy expenditures. Addiction 2006, I 0 I (3):3 I5-322.

6. Grant BF, Stinson FS, Dawson DA, Chou SP, Dufour MC, Compton W, Pickering RP, Kaplan K: Prevalence and co-occurrence of substance use disorders and independent mood and anxiety disorders: results from the National Epidemiologic Survey on Alcohol and Related Conditions. Arch Gen Psychiatry 2004, 6 I (8):807-8I6.

7. Kessler RC, Chiu WT, Demler O, Merikangas KR, Walters EE: Prevalence, severity, and comorbidity of I2-month DSM-IV disorders in the National Comorbidity Survey Replication. Arch Gen Psychiatry 2005, 62(6):617-627.

8. Regier DA, Farmer ME, Rae DS, Locke BZ, Keith SJ, Judd LL, Goodwin FK: Comorbidity of mental disorders with alcohol and other drug abuse. Results from the Epidemiologic Catchment Area (ECA) Study. Jama 1990, 264(19):25II-25।8.

9. Lasser K, Boyd JW, Woolhandler S, Himmelstein DU, McCormick D, Bor DH: Smoking and mental illness: A population-based prevalence study. JAMA 2000, 284(20):2606-26I0.

10. Bakken K, Landheim AS, Vaglum P: Axis I and II disorders as longterm predictors of mental distress: a six-year prospective follow-up of substance-dependent patients. BMC Psychiatry 2007, 7:29.

II. McCrae RR, John OP: An introduction to the Five-Factor Model and its applications. J Pers 1992, 60(2): I75-2 I5.

12. McCrae RR, Terracciano A, 78 Members of the Personality Profiles of Cultures Project: Universal features of personality traits from the observer's perspective: Data from $\mathbf{5 0}$ cultures. J Pers Soc Psychol 2005, 88:547-56I.

13. Terracciano A, McCrae RR: Cross-cultural studies of personality traits and their relevance to psychiatry. Epidemiol Psichiatr Soc 2006, I5:176-184 [http://www.psychiatry.univr.it/page eps/docs/ 20063 Terracciano.pdf].

14. Terracciano A, Costa PT Jr.: Smoking and the Five-Factor Model of personality. Addiction 2004, 99:472-48I.

15. Paunonen SV, Ashton MC: Big five factors and facets and the prediction of behavior. J Pers Soc Psychol 200I, 8 I (3):524-539.

16. Malouff JM, Thorsteinsson EB, Schutte NS: The five-factor model of personality and smoking: a meta-analysis. J Drug Educ 2006, 36(I):47-58.

17. Arai Y, Hosokawa T, Fukao A, Izumi Y, Hisamichi S: Smoking behaviour and personality: $A$ population-based study in Japan. Addiction 1997, 92(8): 1023-I033.

18. Munafo MR, Black S: Personality and smoking status: A longitudinal analysis. Nicotine Tob Res 2007, 9(3):397-404.

19. Gorman DM, Derzon JH: Behavioral traits and marijuana use and abuse: a meta-analysis of longitudinal studies. Addict Behav 2002, 27(2): 193-206.

20. Bogg T, Roberts BW: Conscientiousness and health-related behaviors: a meta-analysis of the leading behavioral contributors to mortality. Psychol Bull 2004, I30(6):887-919.

21. Saiz PA, Gonzalez MP, Paredes B, Martinez S, Delgado JM: Personality and use-abuse of cocaine. Addiciones 200I, I 3(3):47-59.

22. Kilbey MM, Breslau N, Andreski P: Cocaine use and dependence in young adults: associated psychiatric disorders and personality traits. Drug Alcohol Depend 1992, 29(3):283-290.

23. Ball SA, Schottenfeld RS: A five-factor model of personality and addiction, psychiatric, and AIDS risk severity in pregnant and postpartum cocaine misusers. Subst Use Misuse 1997, 32(I):25-4I. 
24. Rosenthal TL, Edwards NB, Ackerman BJ, Knott DH, Rosenthal RH: Substance abuse patterns reveal contrasting personal traits. J Subst Abuse 1990, 2(2):255-263.

25. Brooner RK, Schmidt CW, Herbst JH: Personality trait characteristics of opioid abusers with and without comorbid personality disorders. In Personality disorders and the Five-Factor Model of personality 2nd edition. Edited by: Costa PT], Widiger TA. Washington, DC , American Psychological Association; 2002:249-268.

26. Tremeau F, Darreye A, Leroy B, Renckly V, Ertle S, Weibel H, Khidichian F, Macher JP: [Personality changes in opioid-dependent subjects in a methadone maintenance treatment program]. Encephale 2003, 29(4 Pt I):285-292.

27. Blaszczynski AP, Buhrich N, McConaghy N: Pathological gamblers, heroin addicts and controls compared on the E.P.Q. 'Addiction Scale'. Br J Addict 1985, 80(3):3।5-3।9.

28. Kornor $\mathrm{H}$, Nordvik $\mathrm{H}$ : Five-factor model personality traits in opioid dependence. BMC Psychiatry 2007, 7:37.

29. Eaton WW, Anthony JC, Gallo J, Cai G, Tien A, Romanoski A, Lyketsos C, Chen LS: Natural history of Diagnostic Interview Schedule/DSM-IV major depression. The Baltimore Epidemiologic Catchment Area follow-up. Archives of General Psychiatry 1997, 54:993-999.

30. Folstein M, Folstein S, McHugh P: Mini-Mental State. A practical method for grading the cognitive state of patients for the clinician. Journal of Psychiatric Research 1975, I2:189-198.

31. Costa PT Jr., McCrae RR: Revised NEO Personality Inventory (NEO-PI-R) and NEO Five-Factor Inventory (NEO-FFI) professional manual. Odessa, FL , Psychological Assessment Resources; 1992

32. Terracciano A, Löckenhoff CE, Zonderman AB, Ferrucci L, Costa PT Jr: Personality predictors of longevity: Activity, Emotiona Stability, and Conscientiousness. Psychosomatic Medicine 2008.

33. Löckenhoff CE, Terracciano A, Bienvenu OJ, Patriciu NS, Nestadt G, McCrae RR, Eaton WW, Costa PT Jr: Ethnicity, education, and the temporal stability of personality traits in the East Baltimore Epidemiologic Catchment Area Study. Journal of Research in Personality in press.

34. SPSS: SPSS I3.0 for Windows edition. Chicago, SPSS Inc; 2004

35. Cohen J: Statistical power analysis for the behavioral sciences. second edition. Hillsdale, New Jersey, Lawrence Erlbaum Associates; 1988

36. Whiteside SP, Lynam DR: The Five Factor Model and impulsivity: using a structural model of personality to understand impulsivity. Pers Individ Differ 200I, 30(4):669-689.

37. Gilbert DG, Gilbert BO: Personality, psychopathology, and nic otine response as mediators of the genetics of smoking. Behav Genet 1995, 25(2): I33-147.

38. Terracciano A, Costa PT Jr, McCrae RR: Personality Plasticity After Age 30. Pers Soc Psychol Bull 2006, 32:999-1009.

39. Terracciano A, McCrae RR, Costa PT Jr: Longitudinal trajectories in Guilford-Zimmerman Temperament Survey data in the Baltimore Longitudinal Study of Aging. J Gerontol B Psychol Sci Soc Sci 2006, 6 I (2):PI08-PI I6.

40. Terracciano A, McCrae RR, Brant LJ, Costa PT Jr: Hierarchical linear modeling analyses of NEO-PI-R scales in the Baltimore Longitudinal Study of Aging. Psychol Aging 2005, 20:493-506.

41. Stein JA, Newcomb MD, Bentler PM: Personality and drug use: Reciprocal effects across four years. Personality and Individual Differences 1987, 8:419-430.

42. Parrott AC: Nesbitt's paradox resolved? Stress and arousal modulation during cigarette smoking. Addiction 1998 93(I):27-39.

43. Picciotto MR, Brunzell DH, Caldarone BJ: Effect of nicotine and nicotinic receptors on anxiety and depression. Neuroreport 2002, I 3(9): 1097- I I06.

44. Breslau N, Novak SP, Kessler RC: Daily smoking and the subsequent onset of psychiatric disorders. Psychol Med 2004 34(2):323-333.

45. Piedmont RL: Cracking the plaster cast: Big Five personality change during intensive outpatient counseling. Journal of Research in Personality 2001, 35:500-520.

46. Felitti VJ, Anda RF, Nordenberg D, Williamson DF, Spitz AM, Edwards $\mathrm{V}$, Koss MP, Marks JS: Relationship of childhood abuse and household dysfunction to many of the leading causes of death in adults. The Adverse Childhood Experiences (ACE) Study. Am J Prev Med 1998, I4(4):245-258.
47. Kodl MM, Mermelstein R: Beyond modeling: parenting practices, parental smoking history, and adolescent cigarette smoking. Addict Behav 2004, 29(I): 17-32.

48. Kubicka L, Matejcek Z, Dytrych Z, Roth Z: IQ and personality traits assessed in childhood as predictors of drinking and smoking behaviour in middle-aged adults: a 24- year followup study. Addiction 200I, 96(I I): I6I5-1628.

49. Hampson SE, Goldberg LR, Vogt TM, Dubanoski JP: Forty years on: teachers' assessments of children's personality traits predict self-reported health behaviors and outcomes at midlife. Health Psychol 2006, 25(I):57-64

50. Harakeh Z, Scholte RH, de Vries H, Engels RC: Association between personality and adolescent smoking. Addict Behav 2006, 3 I (2):232-245.

5I. McClernon FJ, Hiott FB, Westman EC, Rose JE, Levin ED: Transdermal nicotine attenuates depression symptoms in nonsmokers: a double-blind, placebo-controlled trial. Psychopharmacology (Berl) 2006, I89(I): I25-I33.

52. Breslau N, Peterson EL, Schultz LR, Chilcoat HD, Andreski P: Major depression and stages of smoking. A longitudinal investigation. Arch Gen Psychiatry 1998, 55(2): 16I-166.

53. Maes HH, Sullivan PF, Bulik CM, Neale MC, Prescott CA, Eaves LJ, Kendler KS: A twin study of genetic and environmental influences on tobacco initiation, regular tobacco use and nicotine dependence. Psychol Med 2004, 34(7): | 25I-I26I.

54. Pilia G, Chen WM, Scuteri A, Orrú M, Albai G, Dei M, Lai S, Usala L, Lai M, Loi P, Mameli C, Vacca L, Deiana M, Masala M, Cao A, Najjar SS, Terracciano A, Nedorezov T, Sharov A, Zonderman AB, Abecasis G, Costa PT, Lakatta E, Schlessinger D: Heritability of Cardiovascular and Personality Traits in 6, 148 Sardinians. PloS Genetics 2006, 2:el 32

55. Hughes JR, Giovino GA, Klevens RM, Fiore MC: Assessing the generalizability of smoking studies. Addiction 1997, 92(4):469-472.

56. Hooten WM, Ames SC, Vickers KS, Hays JT, Wolter TD, Hurt RD, Offord KP: Personality correlates related to tobacco abstinence following treatment. Int J Psychiatry Med 2005 , 35(I):59-74.

57. Brooner RK, Kidorf MS, King VL, Stoller KB, Neufeld KJ, Kolodner K: Comparing adaptive stepped care and monetary-based voucher interventions for opioid dependence. Drug Alcohol Depend 2007, 88( Suppl 2):SI4-23.

58. Berlin I, Covey LS: Pre-cessation depressive mood predicts failure to quit smoking: the role of coping and personality traits. Addiction 2006, I 0 I (12): |8|4-182I.

59. Staiger PK, Kambouropoulos N, Dawe S: Should personality traits be considered when refining substance misuse treatment programs? Drug Alcohol Rev 2007, 26(I): 17-23.

60. Miller $\mathrm{T}$ : The psychotherapeutic utility of the five-factor model of personality: A clinician's experience. Journal of Personality Assessment 1991, 57:415-433.

61. Rhodes T, Kimber J, Small W, Fitzgerald J, Kerr T, Hickman M, Holloway G: Public injecting and the need for 'safer environment interventions' in the reduction of drug-related harm. Addiction 2006, I 0 I (I 0): I 384-I393.

62. Frieden TR, Mostashari F, Kerker BD, Miller N, Hajat A, Frankel M: Adult tobacco use levels after intensive tobacco control measures: New York City, 2002-2003. Am J Public Health 2005 , 95(6): $1016-1023$

\section{Pre-publication history}

The pre-publication history for this paper can be accessed here:

http://www.biomedcentral.com/1471-244X/8/22/pre pub 